Research Article

\title{
Experimental Research on Mechanical and Energy Characteristics of Reinforced Rock under Dynamic Loading
}

\author{
Xinxi Liu, ${ }^{1}$ Yu Li $\mathbb{D}^{1},{ }^{1}$ Fujun Zhao $\mathbb{D}^{2},{ }^{2}$ Yanming Zhou, ${ }^{1}$ Weiwei Wang, ${ }^{1}$ and Shengnan $\mathrm{Li}^{1}$ \\ ${ }^{1}$ School of Civil Engineering, Changsha University of Science \& Technology, Changsha 410114, China \\ ${ }^{2}$ School of Resource Environment and Safety Engineering, Hunan University of Science and Technology, Xiangtan 411201, China
}

Correspondence should be addressed to Yu Li; 1986740197@qq.com

Received 31 July 2019; Revised 6 October 2019; Accepted 10 October 2019; Published 11 November 2019

Academic Editor: Luca Landi

Copyright (c) 2019 Xinxi Liu et al. This is an open access article distributed under the Creative Commons Attribution License, which permits unrestricted use, distribution, and reproduction in any medium, provided the original work is properly cited.

The properties of anchored surrounding rock may vary considerably under complex geological and stress conditions, especially dynamic loading in deep mining. Therefore, comprehensive study of the reinforced mechanism is required to prevent failures associated with deep mining. In this paper, with sandstone as matrix and steel bar as bolt, the dynamic compression test of reinforced rock was carried out by using a $50 \mathrm{~mm}$ rod diameter split Hopkinson pressure bar (SHPB) test device. The mechanical and energy characteristics of reinforced rock under dynamic loading were analyzed. The results show that the dynamic strength of reinforced sample is greater than that of unreinforced sample and increases with the increase of the strain rate. The reflected energy and absorbed energy increase with the increase of incident energy, while the transmitted energy increases slightly. The higher the strain rate, the larger the energy dissipation rate and the higher the degree of fragmentation. It shows that the energy dissipation characteristic reflects the internal damage process to some extent. Compared with the results of unreinforced samples, the reflected energy of reinforced samples significantly increases and the absorbed energy will significantly decrease. It can be seen that the bolt can reduce absorbed energy of surrounding rock, thereby improving the stability of roadway surrounding rock. The results may provide reference for the stability of deep roadway and support design.

\section{Introduction}

Rockbolts are considered as a simple, safe, and economical rock mass reinforcement technology, which are widely used in mines, slopes, tunnels, and other geotechnical engineering, and have achieved good economic and social benefits [1]. Rockbolt performance and reinforcement are influenced by geological and stress conditions $[2,3]$, especially affected by impact loading, which are suspected as the great challenges to the reinforcement mechanism and support design $[4,5]$.

In recent decades, many scholars carried out lots of laboratory and numerical tests, complemented by theoretical analysis, to study the mechanism of anchored rock. In roadway support, the anchor housing is often installed in sections over a short section with one resin charge or using an expansion head [6,7]. Carranza-Torres [8] proposed a closed-form solution of rockbolt reinforcement around tunnels, and numerical analysis confirmed that the bolt plays an important role in increasing the tunnel confining pressure and controlling the surrounding rock deformation. Zhao and Yang [9] designed the pull test of bolt with crack based on the separation defect in the anchorage area and analyzed the influence of crack on axial stress and shear stress distribution of bolt. Zhang et al. [10] analyzed the mechanical properties of reinforced rock mass with crossflaws and obtained that the compressive strength of crossflaws rock is higher than that of single-flaw rock. A new analytical model that represents the behavior of reinforced ground near a circular underground opening in a homogeneous, uniform stress field has been developed by considering the interaction behaviors between the grouted rockbolt and ground [11]. Moosavi and Grayeli [12] simulated rockbolt support problems by using the DDA method and mainly focused on the basic performance of the support system. Freeman [13] first proposed the concept of "neutral 
point" by analyzing the full-length bonded anchor in the test tunnel, which is widely recognized and applied, but the position of "neutral point" is difficult to determine.

In practical rock engineering, rock mass is subjected to static load and will also be affected by dynamic loads [14], such as impact, seismic, explosion, earthquake, and blasting. At present, some research studies have been carried out on the dynamic mechanical response of rock [15-19]. Li et al. [16] analyzed the cracking of single-crack marble specimen under impact loading based on experimental study. For the difficulty of studying the failure process of underground rock, an experimental method is proposed to explore dynamic failure process of prestressed rock specimen with a circular hole [17]. Zhang et al. [18] and Hao et al. [19] studied the effects of bedding on the dynamic and static properties of coal and rock, respectively. However, few research studies have been carried out on the dynamic response of the rockbolt and reinforced surrounding rock [20-23]. And due to complicated geological and mining conditions, a more complete understanding of the mechanical property of reinforced rock is required. Therefore, in this study, dynamic compression tests of sandstones reinforced by using a steel bar were conducted. The mechanical and energy characteristics of the reinforced rock under dynamic loading were investigated, and the results may provide reference for the stability of deep roadway and support design.

\section{Specimen Preparation and Experimental Methods}

2.1. Specimen Preparation. The sandstone used in the experiment was taken from Linyi, Shandong Province, China. According to the standard GB/T50266-2013 [24], standard cylindrical samples were made (A-1 and A-2). Mechanical parameters of the standard cylindrical specimen were obtained by using the RMT-150C rock mechanics test system (see Figure 1). The compression test was carried out by displacement control with a loading rate of $0.002 \mathrm{~mm} / \mathrm{s}$. Two displacement sensors with a range of $2 \mathrm{~mm}$ were used during the test to determine transverse deformation of sandstone samples. The average compressive strength and elastic modulus of the standard cylindrical specimen are $53.2 \mathrm{MPa}$ and $4.3 \mathrm{GPa}$, respectively. Meanwhile, the sandstone specimen was observed by using a scanning electron microscope with SU3500, as shown in Figure 2. From the figure, it is observed that the internal microstructure of the rock is tight and mainly consists of quartz and feldspar.

The test samples, shown in Figure 3(a), were used for unreinforced and reinforced tests and labeled as US and RS, respectively. For example, "US-1" represents the \#1 unreinforced specimen and "RS-1" represents the \#1 reinforced specimen. The sample size is $50 \mathrm{~mm}$ in thickness and $50 \mathrm{~mm}$ in diameter. For the reinforced specimen, the bolt arrangement is shown in Figure 3(b). A hole with a diameter of $3 \mathrm{~mm}$ was drilled through the center side of the specimen. In this experiment, a steel bar was used to simulate the rockbolt. The steel bar was inserted into the hole and anchored on the rock with resin (the resin used is the same as in mine conditions). The steel bar is $60 \mathrm{~mm}$ long, $2 \mathrm{~mm}$ wide, and $2 \mathrm{~mm}$ thick with

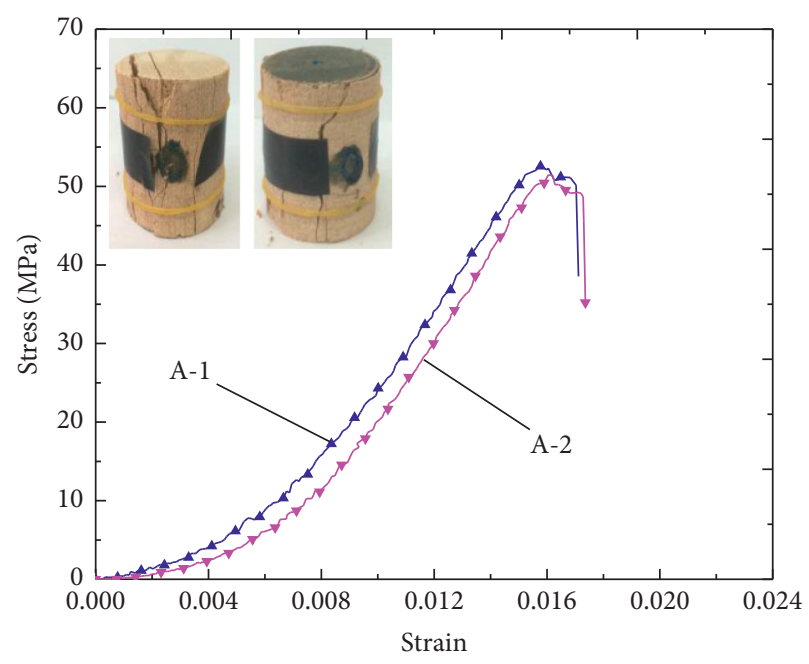

FIgURE 1: Mechanical properties of the sandstone.

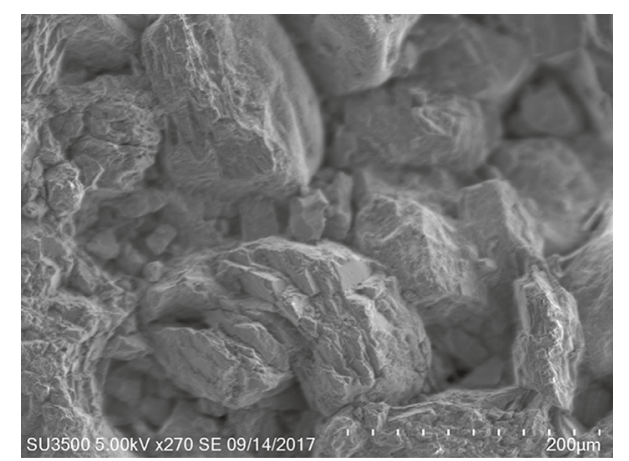

FIgURE 2: Electron microscopy of the sandstone.

the tensile strength of $600 \mathrm{MPa}$, shear strength of $400 \mathrm{MPa}$, and elastic modulus of $210 \mathrm{GPa}$. Since the SHPB test can only directly control the impact pressure and cannot directly set different strain rates, the impact compression test was conducted under the impact pressure range of $0.35 \sim 0.6 \mathrm{MPa}$.

2.2. Test System. The dynamic compression test of rock was carried out by using a $50 \mathrm{~mm}$ rod diameter split Hopkinson pressure bar (SHPB) test device. Figure 4 illustrates the schematic of the SHPB system, which mainly consists of two parts, i.e., three bars (an incident bar with a length of $2 \mathrm{~m}$, a transmitted bar with a length of $1.5 \mathrm{~m}$, and an absorbing bar with a length of $0.5 \mathrm{~m}$ ) and a data acquisition subsystem. A semisine wave was generated by a special shape striker and used as the loading stress wave to ensure that the stress was even before failure of the specimens $[25,26]$. The incident, transmitted, and absorbing bars were made of $40 \mathrm{Cr}$ alloy steel with a density of $7810 \mathrm{~kg} / \mathrm{m}^{3}$, longitudinal wave velocity of $5410 \mathrm{~m} / \mathrm{s}$, and elastic modulus of $250 \mathrm{GPa}$. The strain gauge model on the incident and transmitted bars is BE120$5 \mathrm{AA}$ and the resistance value is $120 \Omega$. The measurement base has a length of $8.5 \mathrm{~mm}$ and a width of $4 \mathrm{~mm}$. The KD 6009 strain amplifier is used to collect data signals. 


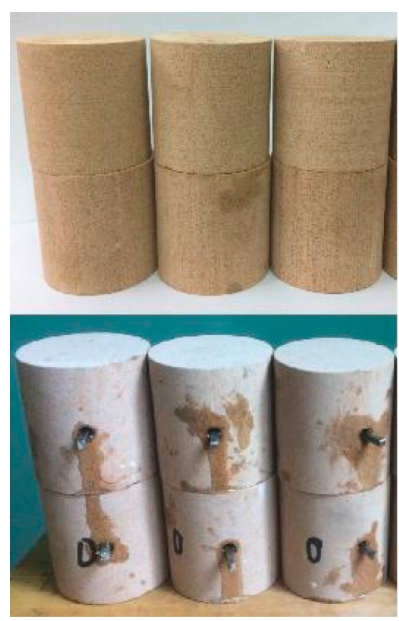

(a)

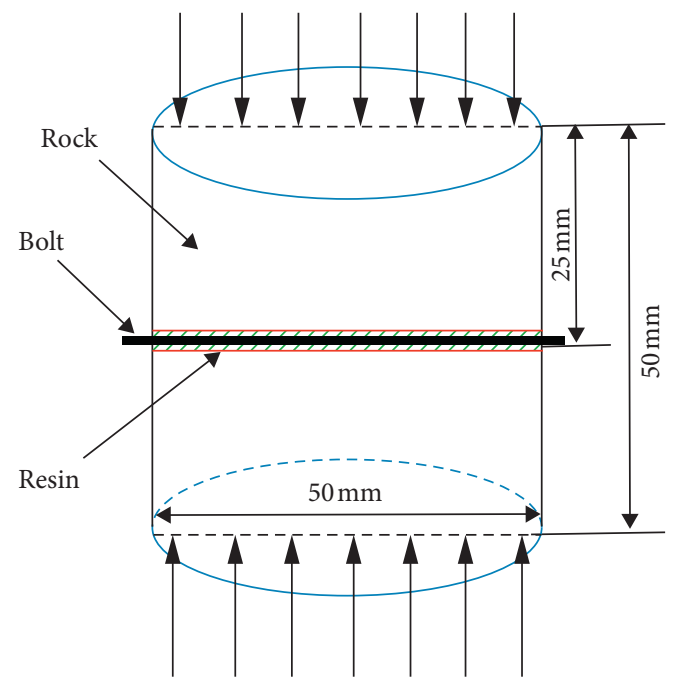

(b)

Figure 3: Specimen preparation. (a) The unreinforced and reinforced samples. (b) The bolt arrangement.

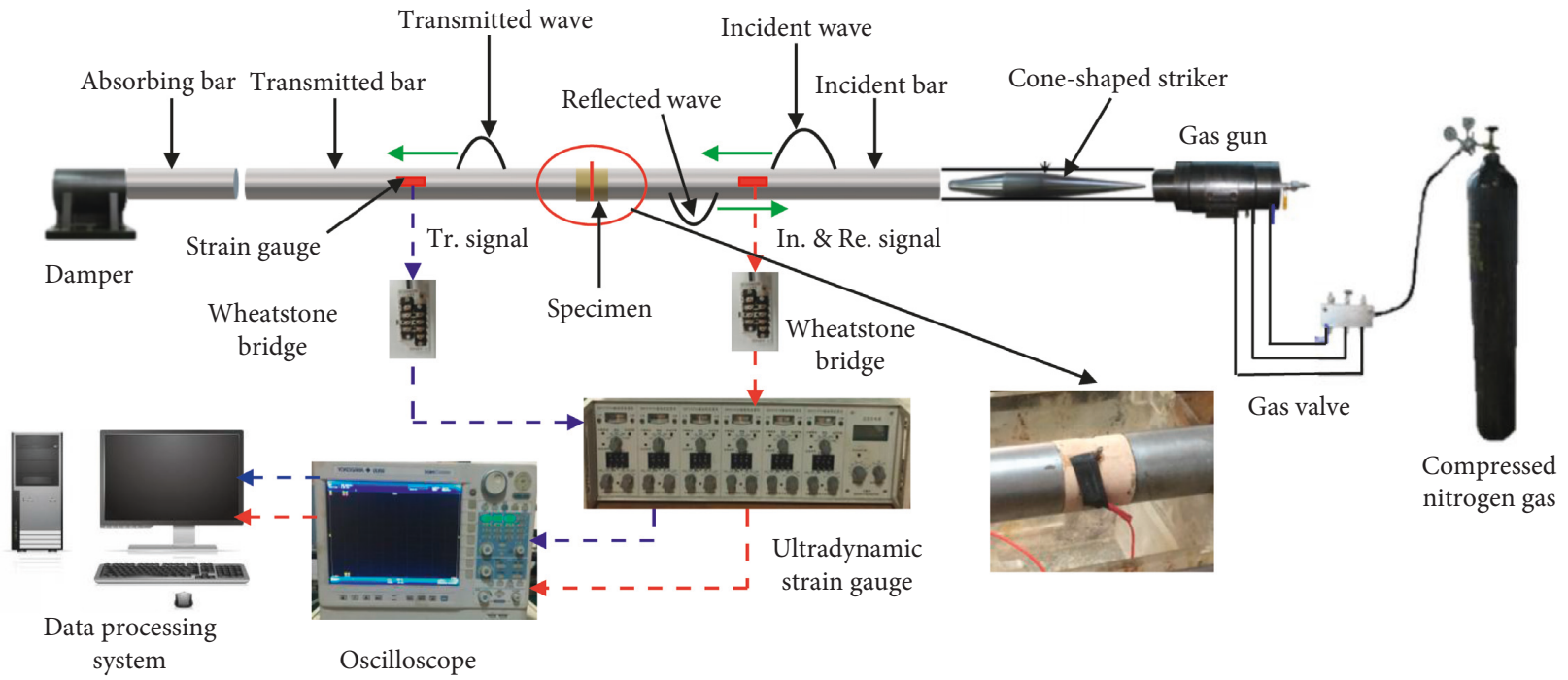

FIgure 4: Schematic of the SHPB system.

According to the stress wave signals collected by strain gauges on the incident and transmitted bars, the stress, strain, and strain rate of the specimen during impact loading were calculated based on the one-dimensional stress wave theory and stress uniformity hypothesis. The calculation formula is as follows [25]:

$$
\begin{aligned}
& \sigma(t)=\frac{A_{\mathrm{e}} E_{\mathrm{e}}}{2 A_{\mathrm{s}}}\left[\varepsilon_{\mathrm{I}}(t)+\varepsilon_{\mathrm{R}}(t)+\varepsilon_{\mathrm{T}}(t)\right], \\
& \varepsilon(t)=\frac{C_{\mathrm{e}}}{L_{\mathrm{s}}} \int_{0}^{t}\left[\varepsilon_{\mathrm{I}}(t)-\varepsilon_{\mathrm{R}}(t)-\varepsilon_{\mathrm{T}}(t)\right] \mathrm{d} t, \\
& \dot{\varepsilon}(t)=\frac{C_{\mathrm{e}}}{L_{\mathrm{s}}}\left[\varepsilon_{\mathrm{I}}(t)-\varepsilon_{\mathrm{R}}(t)-\varepsilon_{\mathrm{T}}(t)\right],
\end{aligned}
$$

where $\sigma(t), \varepsilon(t)$, and $\dot{\varepsilon}(t)$ are the stress, strain, and strain rate, respectively. $A_{\mathrm{s}}$ and $A_{\mathrm{e}}$ are the area of the specimen and the bar, respectively. $E_{\mathrm{e}}$ is the elastic modulus of bars. $\varepsilon_{\mathrm{I}}(t)$, $\varepsilon_{\mathrm{R}}(t)$, and $\varepsilon_{\mathrm{T}}(t)$ are the incident wave, reflected wave, and transmitted wave, respectively. $L_{\mathrm{s}}$ is the length of specimen. $C_{e}$ is the wave velocity of bars.

\section{Experimental Results}

3.1. Stress Equilibrium. For dynamic compression tests, it is necessary to eliminate wave dispersion and inertia effect to ensure the accuracy of test results. Therefore, the stress equilibrium at the two ends of the specimen before failure was reached. In this paper, the typical stress wave signals of samples US- 4 and RS- 4 from the dynamic loading experiment are shown in Figure 5. With increase of loading time, the curve of the sum of the incident and reflected waves (In. + Re.) almost overlaps with that of the stress (Tr.), indicating that the specimen is basically in a stress equilibrium 
state during this dynamic loading process, and the test data are reliable.

3.2. Stress-Strain Curve Characteristics. The strain signals on the incident and transmitted bars were recorded by using the ultradynamic strain gauge. Based on equations (1) and (2), the strain signals on the incident and transmitted bars can be converted into the stress and strain signals of the specimen during dynamic loading. The stress-strain curves of samples under dynamic loading are shown in Figure 6.

It can be seen from Figure 6 that the stress-strain curve of the specimen can be divided into the phase of linear elasticity, plasticity, and failure under dynamic loading. Due to the high impact velocity, the phase of macro-microscopic defect closure compaction is extremely short, and there is basically no sunken section in the stress-strain curve, which directly enters the phase of linear elasticity, and the stress increases linearly with the strain. Then, the phase of plasticity begins, and the slope of the curve decreases. Finally, the ultimate strength of the specimen is reached, accompanied by the failure of the specimen.

3.3. Dynamic Compressive Strength. The mechanical parameters of the specimens under impact loading are shown in Table 1. In order to analyze the effect of the loading rate and bolt on rock strength, the test results are plotted as scatter plot, as shown in Figure 7.

Figure 7 shows that the dynamic compressive strength of US and RS samples increases with the increase of strain rate. Moreover, the dynamic elastic modulus of the specimen is different under different strain rates (Figure 7), and the dynamic elastic modulus increases with the increase of strain rate. It shows that the rock specimen has a strong correlation with the strain rate. The dynamic compressive strength of RS samples is slightly higher than that of US samples. The results show that the strength and deformation ability of rock are improved by applying rockbolt and reflecting the obvious correlation of strain rate.

\section{Energy Characteristics}

4.1. Energy Calculation. According to the energy balance [27], the absorbed energy of rock during impact loading can be calculated using the following equation [28]:

$$
W_{\mathrm{a}}=W_{\mathrm{I}}-\left(W_{\mathrm{R}}+W_{\mathrm{T}}\right),
$$

where $W_{\mathrm{a}}, W_{\mathrm{I}}, W_{\mathrm{R}}$, and $W_{\mathrm{T}}$ are the absorbed energy, incident energy, reflected energy, and transmitted energy, respectively. $W_{\mathrm{I}}, W_{\mathrm{R}}$, and $W_{\mathrm{T}}$ can be calculated using the following equations [28]:

$$
\begin{gathered}
W_{\mathrm{I}}=E_{\mathrm{e}} A_{\mathrm{e}} C_{\mathrm{e}} \int_{0}^{t} \varepsilon_{\mathrm{I}}^{2}(t) \mathrm{d} t, \\
W_{\mathrm{R}}=E_{\mathrm{e}} A_{\mathrm{e}} C_{\mathrm{e}} \int_{0}^{t} \varepsilon_{\mathrm{R}}^{2}(t) \mathrm{d} t,
\end{gathered}
$$

$$
W_{\mathrm{T}}=E_{\mathrm{e}} A_{\mathrm{e}} C_{\mathrm{e}} \int_{0}^{t} \varepsilon_{\mathrm{T}}^{2}(t) \mathrm{d} t
$$

The results show that the absorbed energy of rock is mainly converted into the energy dissipation, kinetic energy, and other energy, among which the energy dissipation of specimen fragmentation is more than $90 \%$ of the absorbed energy [29]. Therefore, the absorbed energy is approximately substituted for the energy dissipation of specimen fragmentation in this study. In order to measure the strength of energy dissipation of the US and RS specimens under different loading rates, it is generally characterized by the energy dissipation rate, which can be calculated as

$$
N=\frac{W_{\mathrm{a}}}{W_{\mathrm{I}}}
$$

where $N$ is the energy dissipation rate.

4.2. Analysis of Energy-Time Curves. Certainly, the deformation and destruction of rock is the whole process of the energy dissipation and energy release [30-32]. Therefore, the energy dissipation characteristics of samples during impact loading are analyzed from the viewpoint of energy. According to equations (4)-(7), the strain-time curves of specimen are obtained by the experiment. The energy-time curves of all samples are plotted in Figures 8 and 9 by calculating.

It can be seen from Figures 8 and 9 that the same phenomenon occurs for US and RS samples under impact loading. The incident energy, reflected energy, and absorbed energy increase rapidly compared with the transmitted energy with the propagation of the stress wave, and their values maintain stable after reaching a certain value, while the transmitted energy-time curve is approximately a horizontal line. Based on the stress-time curve and energy-time curve, we can find that the appearance of maximum absorption energy indicates the failure of the US and RS samples [33].

4.3. Energy Change Characteristics. Test results of the energy distribution of samples under impact loading are shown in Table 2. In order to analyze the effect of loading rate and bolt on energy characteristics, the test results are plotted as scatter plot, as shown in Figures 10 and 11.

Because the generation of incident energy is caused by the impact between the striker bar and incident bar, the value of incident energy is determined only by the velocity of the impact bar. In this study, loading rates are the single factor, and the sample type (US and RS samples) has no effect on the incident energy. Figure 10(a) shows that the reflected energy of all samples increases linearly with the increase of incident energy, and the transmitted energy increases slightly. The absorbed energy of specimen increases as a power function with the incident energy (Figure 10(b)). As can be seen from Table 2, most of the energy is dissipated in the form of reflected wave with increase in the incident energy, which is consistent with the results of $\mathrm{Li}$ et al. [34]. 


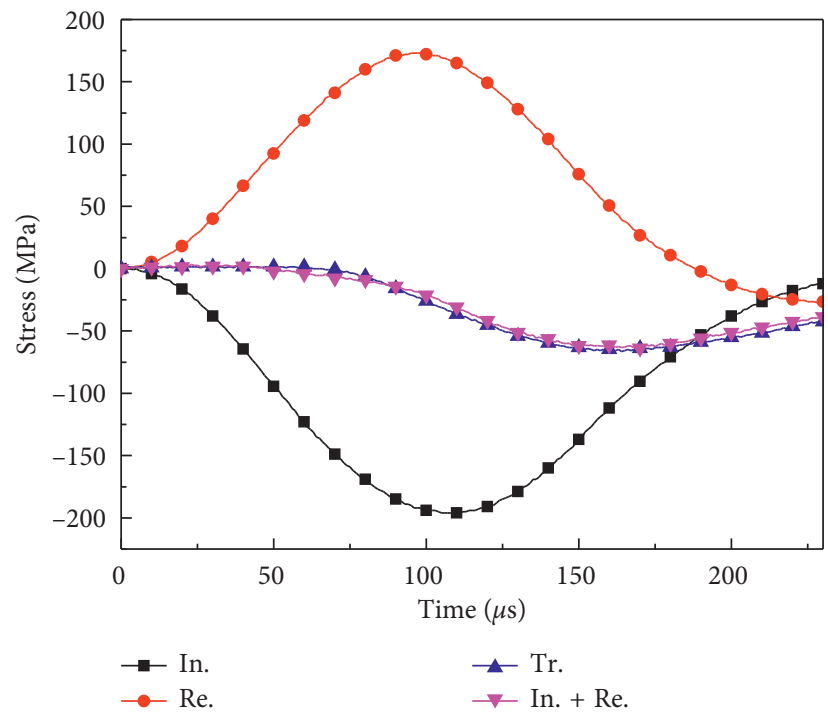

(a)

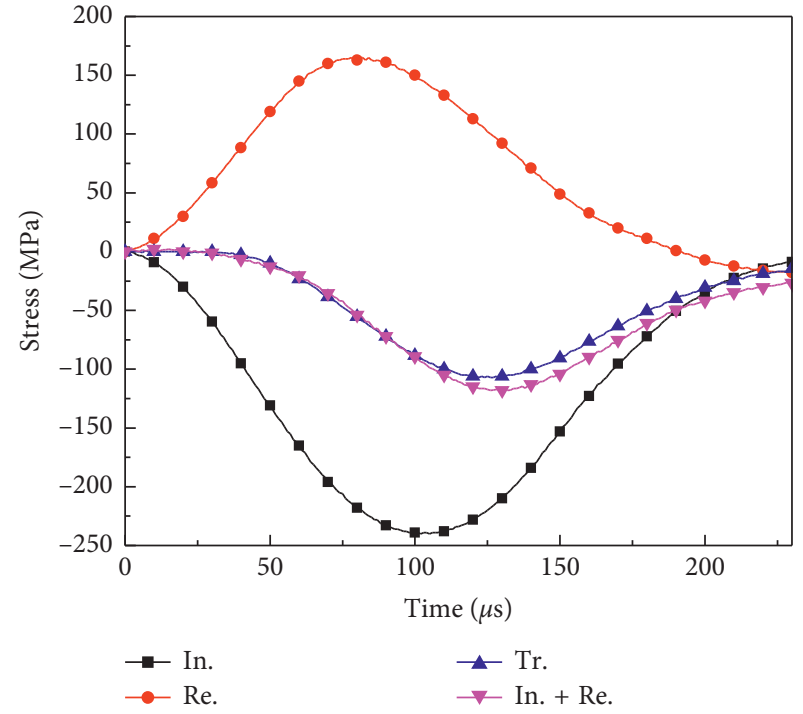

(b)

FIgURE 5: Typical dynamic stress equilibrium results at unreinforced and reinforced conditions. (a) US-4. (b) RS-4.

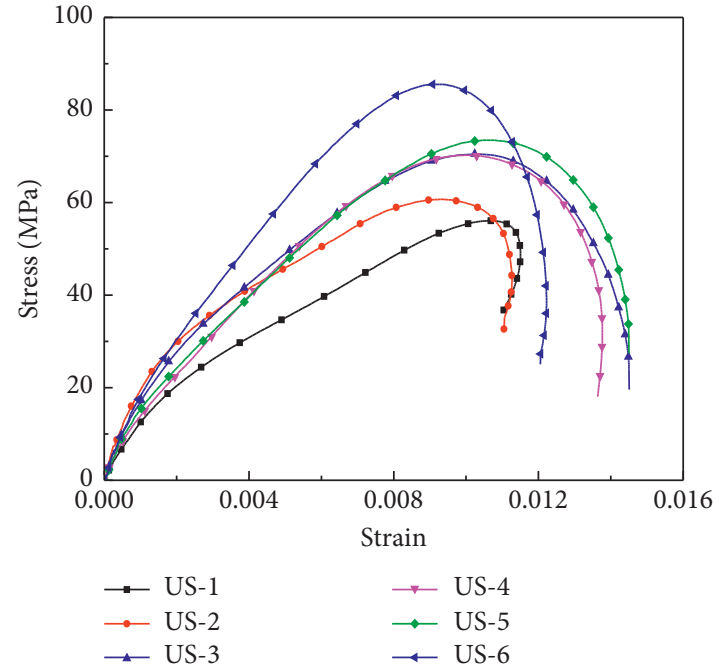

(a)

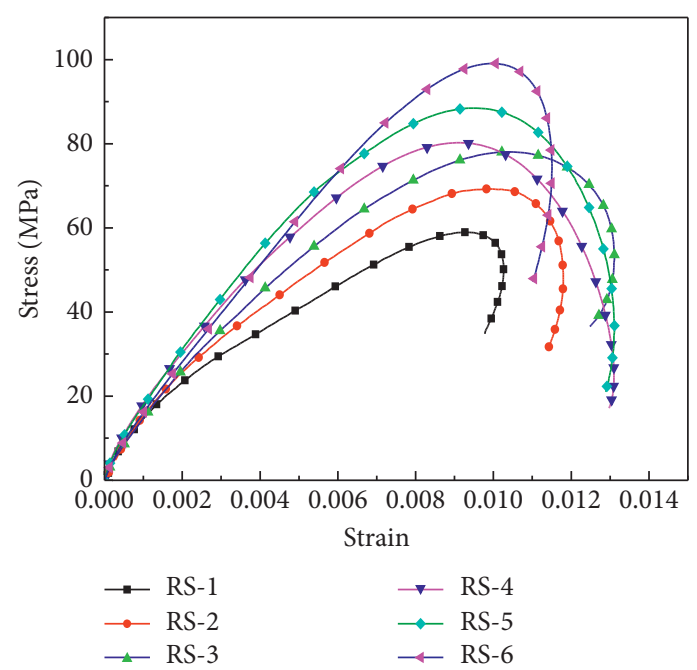

(b)

FIGURE 6: Stress-strain curves of samples under dynamic loading. (a) Unreinforced samples. (b) Reinforced samples.

TABLE 1: The mechanical parameters of samples under dynamic loading.

\begin{tabular}{|c|c|c|c|c|c|c|c|}
\hline $\begin{array}{l}\text { Specimen } \\
\text { no. }\end{array}$ & $\begin{array}{l}\text { Strain rate } \\
\left(\mathrm{s}^{-1}\right)\end{array}$ & $\begin{array}{c}\text { Compressive strength } \\
(\mathrm{MPa})\end{array}$ & $\begin{array}{c}\text { Elastic modulus } \\
(\mathrm{GPa})\end{array}$ & $\begin{array}{c}\text { Specimen } \\
\text { no. }\end{array}$ & $\begin{array}{l}\text { Strain rate } \\
\qquad\left(\mathrm{s}^{-1}\right)\end{array}$ & $\begin{array}{c}\text { Compressive strength } \\
(\mathrm{MPa})\end{array}$ & $\begin{array}{c}\text { Elastic modulus } \\
(\mathrm{GPa})\end{array}$ \\
\hline US-1 & 51 & 56.1 & 5.9 & RS-1 & 49 & 59.0 & 6.3 \\
\hline US-2 & 61 & 60.7 & 6.2 & RS-2 & 69 & 69.2 & 6.7 \\
\hline US-3 & 73 & 70.4 & 6.9 & RS-3 & 80 & 77.9 & 7.4 \\
\hline US-4 & 77 & 71.4 & 7.2 & RS-4 & 87 & 80.5 & 7.6 \\
\hline US-5 & 85 & 73.3 & 7.3 & RS-5 & 93 & 88.0 & 8.8 \\
\hline US-6 & 98 & 85.5 & 8.4 & RS-6 & 105 & 99.4 & 9.4 \\
\hline
\end{tabular}

Figure 11 shows that there is an exponential relation between the energy dissipation rate of samples and strain rate. The failure of sample becomes more severe with the strain rate, and the failure mode of sample develops from cleavage to fragmentation. That is to say, more energy was used to generate new cracks in the samples with the 


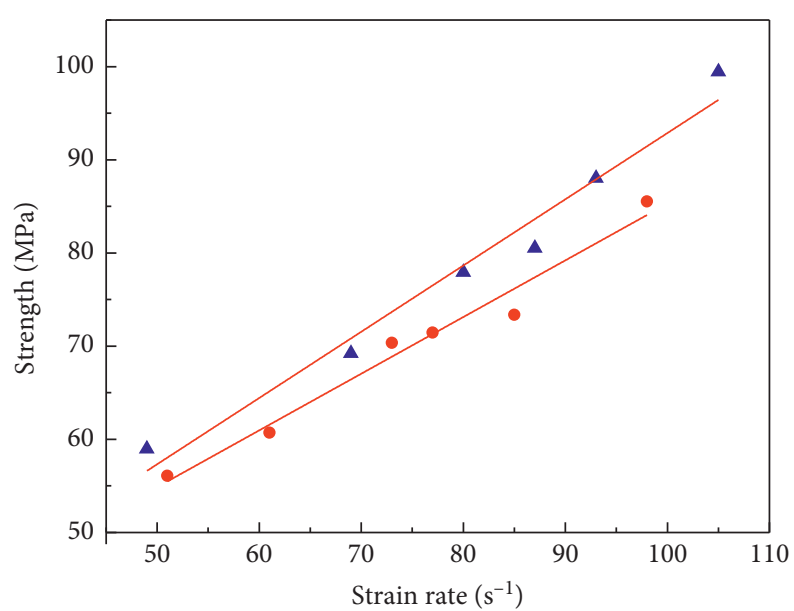

- US specimens

- RS specimens

FIgURE 7: Dynamic strength under different strain rates.

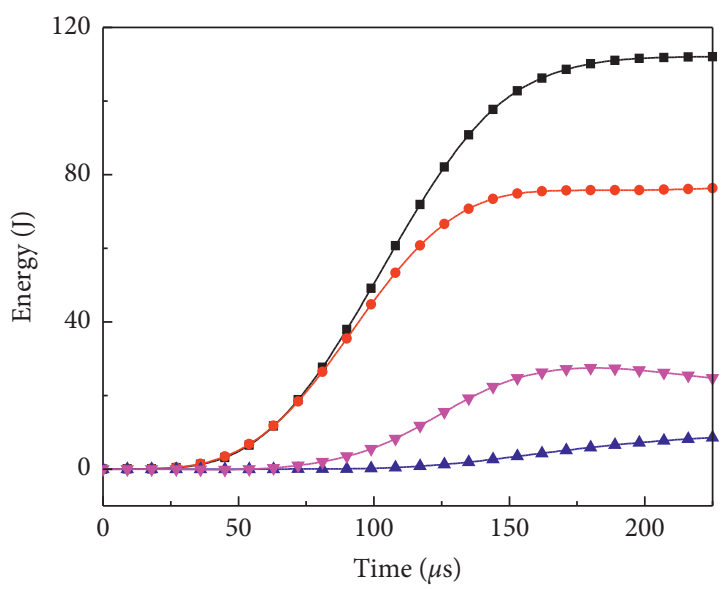

$\rightarrow$ Incident energy $\rightarrow$ Transmitted energy

$\rightarrow$ Reflected energy $\rightarrow$ Absorbed energy

(a)

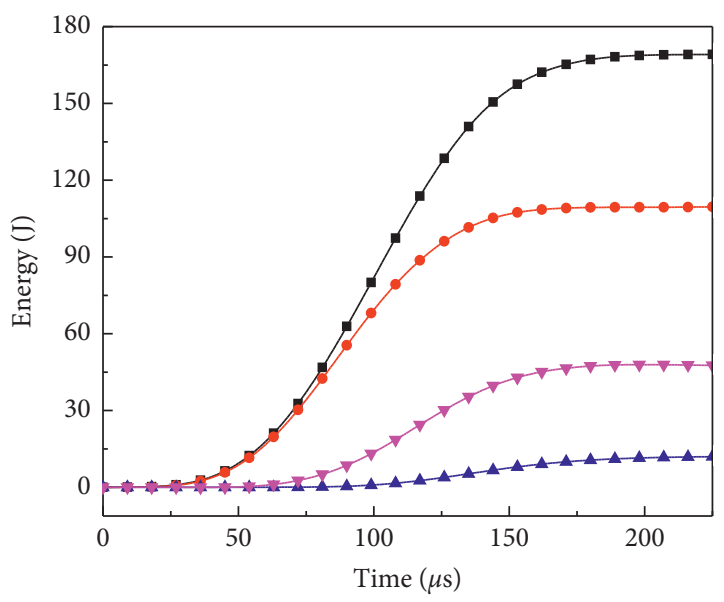

$\rightarrow$ Incident energy $\quad \_$Transmitted energy

- Reflected energy $\rightarrow$ Absorbed energy

(c)

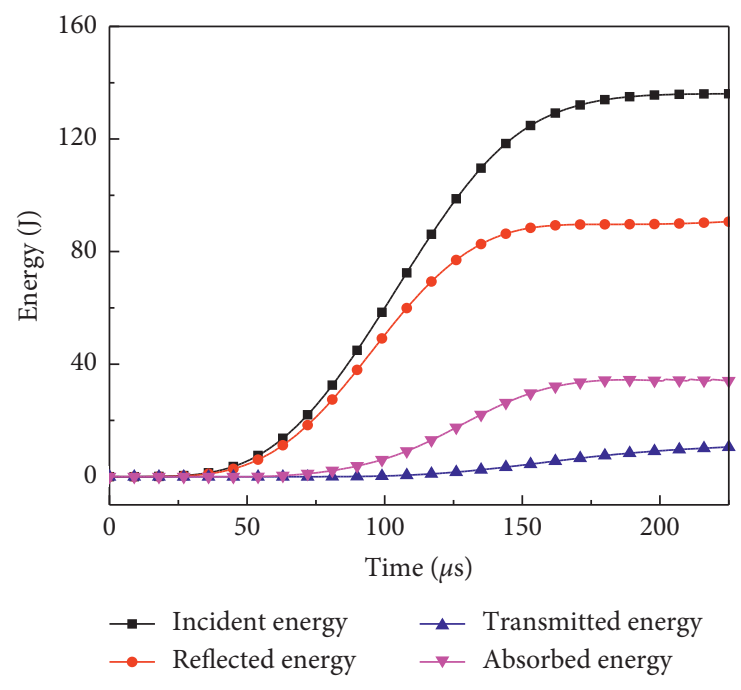

(b)

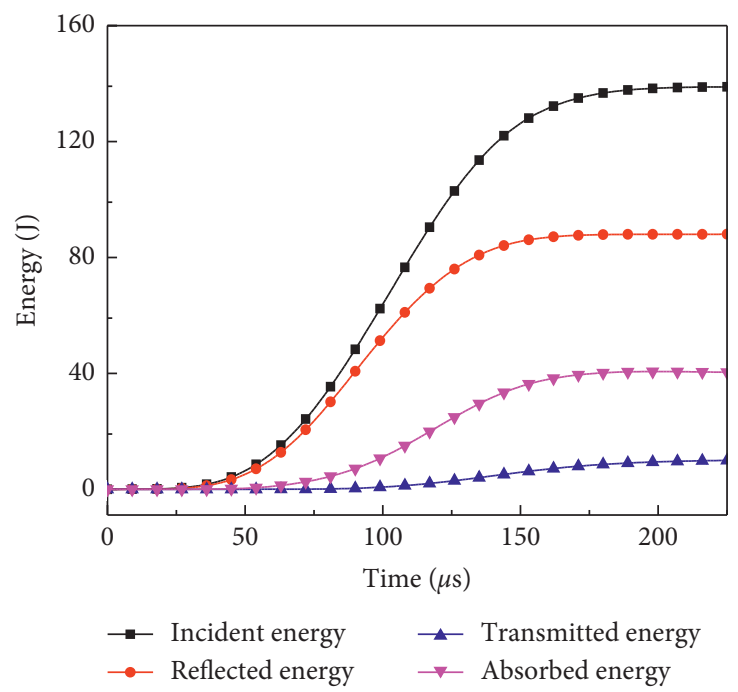

(d)

Figure 8: Continued. 


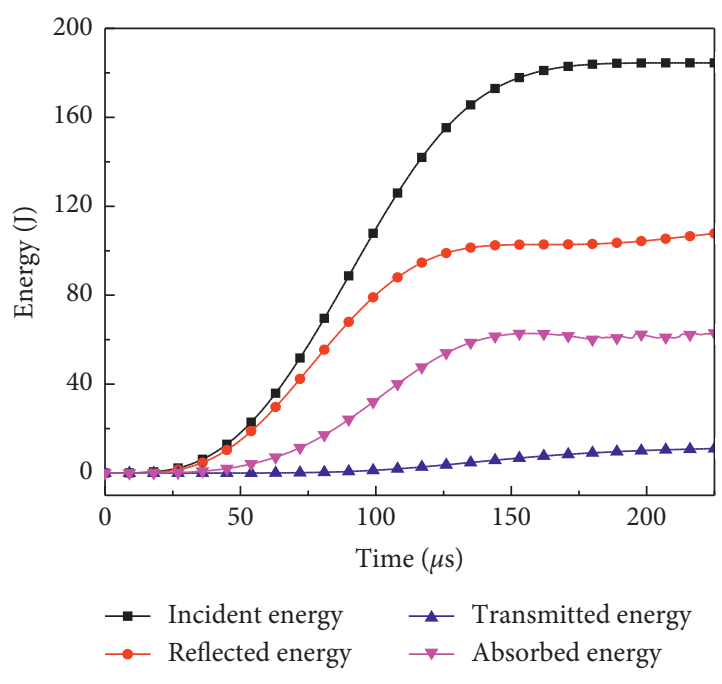

(e)

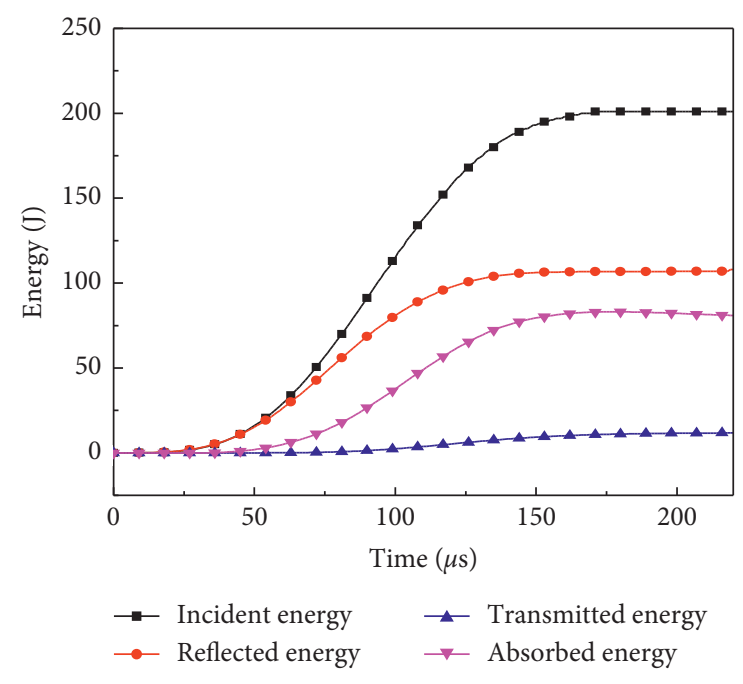

(f)

FIGURE 8: Energy-time curves of samples under impact loading. (a) US-1. (b) US-2. (c) US-3. (d) US-4. (e) US-5. (f) US-6.

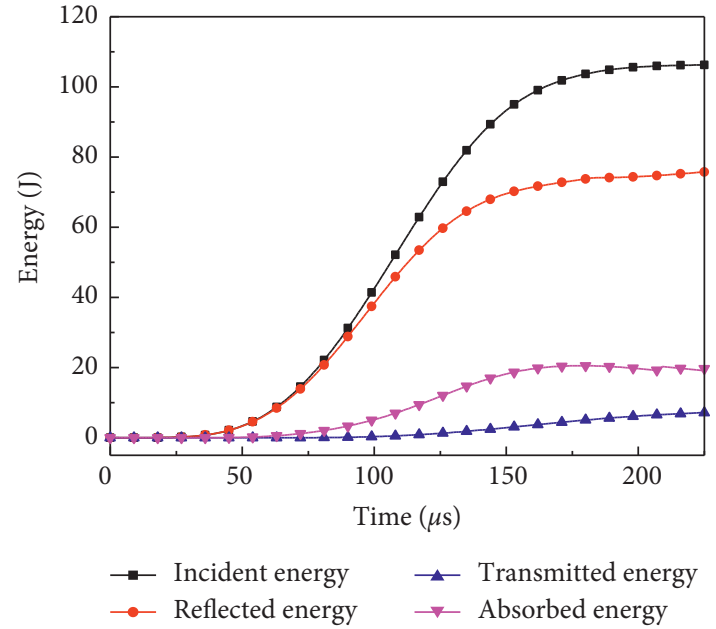

(a)

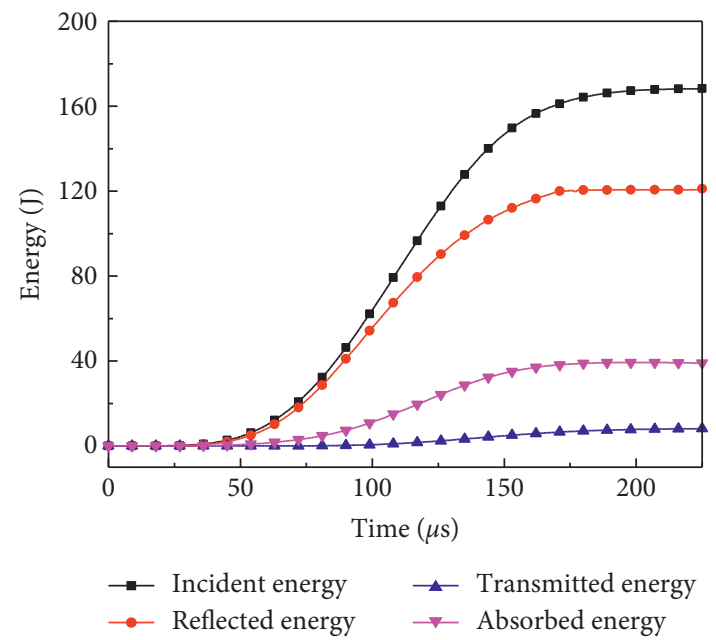

(c)

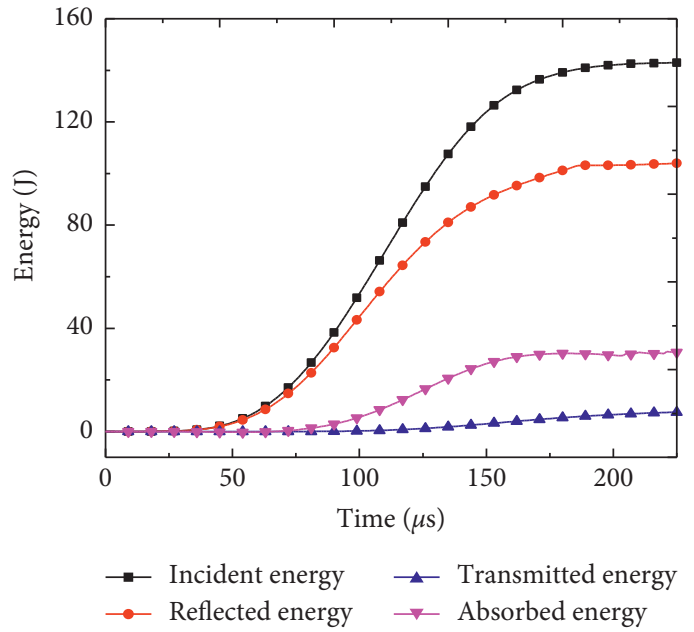

(b)

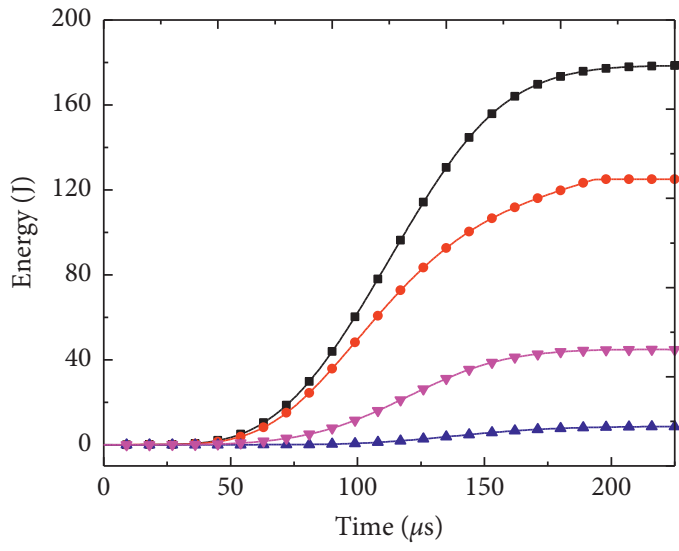

$\rightarrow$ Incident energy $\rightarrow$ Transmitted energy

(d)

Figure 9: Continued. 


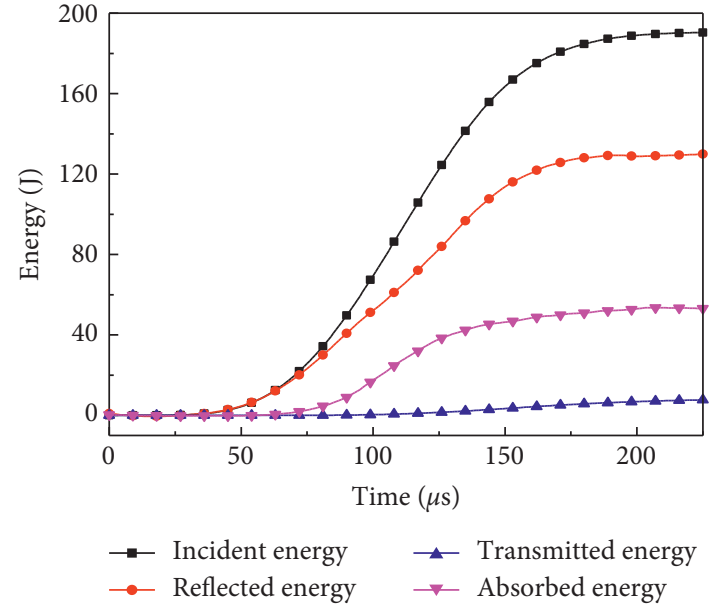

(e)

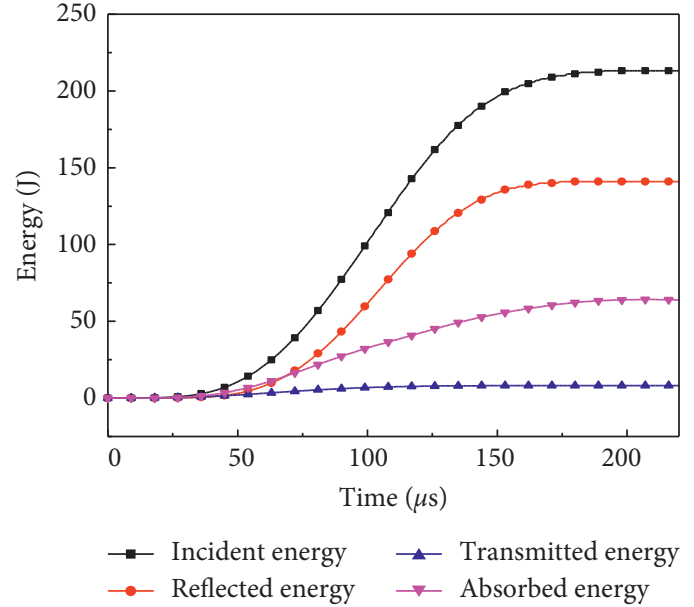

(f)

FIgURE 9: Energy-time curves of samples under impact loading. (a) RS-1. (b) RS-2. (c) RS-3. (d) RS-4. (e) RS-5. (f) RS-6.

TABLE 2: Test results of the energy distribution of samples.

\begin{tabular}{|c|c|c|c|c|c|c|}
\hline $\begin{array}{l}\text { Specimen } \\
\text { no. }\end{array}$ & $\begin{array}{l}\text { Strain rate } \\
\left(\mathrm{s}^{-1}\right)\end{array}$ & $\begin{array}{c}\text { Incident energy } \\
(\mathrm{J})\end{array}$ & $\begin{array}{l}\text { Reflected energy } \\
(\mathrm{J})\end{array}$ & $\begin{array}{l}\text { Transmitted energy } \\
(\mathrm{J})\end{array}$ & $\begin{array}{c}\text { Absorbed energy } \\
(\mathrm{J})\end{array}$ & $\begin{array}{l}\text { Energy dissipation } \\
\text { rate }\end{array}$ \\
\hline US-1 & 51 & 112.20 & 76.76 & 9.63 & 25.81 & 0.23 \\
\hline US-2 & 61 & 137.13 & 91.78 & 11.07 & 34.28 & 0.25 \\
\hline US-3 & 73 & 156.24 & 99.55 & 11.38 & 45.31 & 0.29 \\
\hline US-4 & 77 & 150.36 & 97.54 & 10.72 & 42.10 & 0.28 \\
\hline US-5 & 85 & 184.51 & 110.32 & 11.46 & 62.73 & 0.34 \\
\hline US-6 & 98 & 200.72 & 108.07 & 11.72 & 80.93 & 0.40 \\
\hline RS-1 & 49 & 106.18 & 78.16 & 7.67 & 20.35 & 0.19 \\
\hline RS-2 & 69 & 141.35 & 103.72 & 7.95 & 29.68 & 0.21 \\
\hline RS-3 & 80 & 168.27 & 121.25 & 8.32 & 38.70 & 0.23 \\
\hline RS-4 & 87 & 178.62 & 125.31 & 8.65 & 44.66 & 0.25 \\
\hline RS-5 & 93 & 190.56 & 131.00 & 8.11 & 51.45 & 0.27 \\
\hline RS-6 & 105 & 213.15 & 141.06 & 8.15 & 63.94 & 0.30 \\
\hline
\end{tabular}

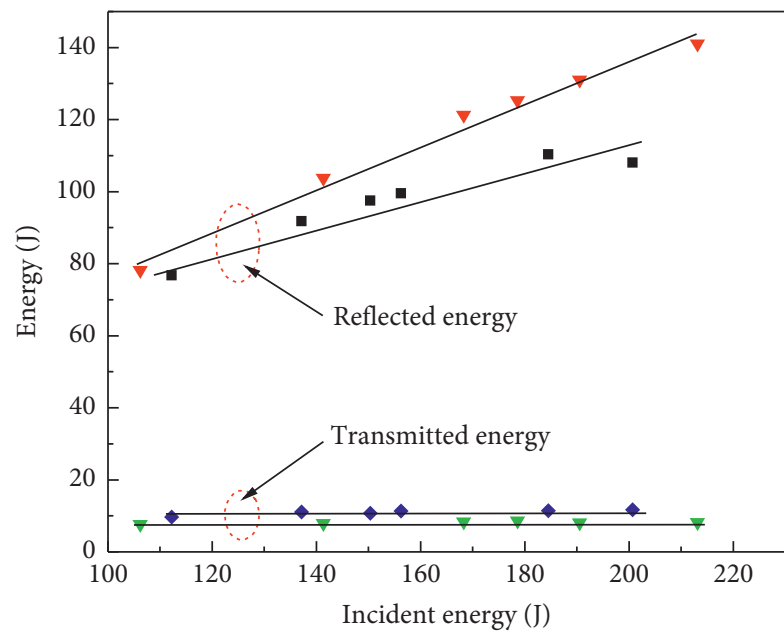

- US specimens

$\checkmark$ RS specimens
- US specimens

$\checkmark$ RS specimens

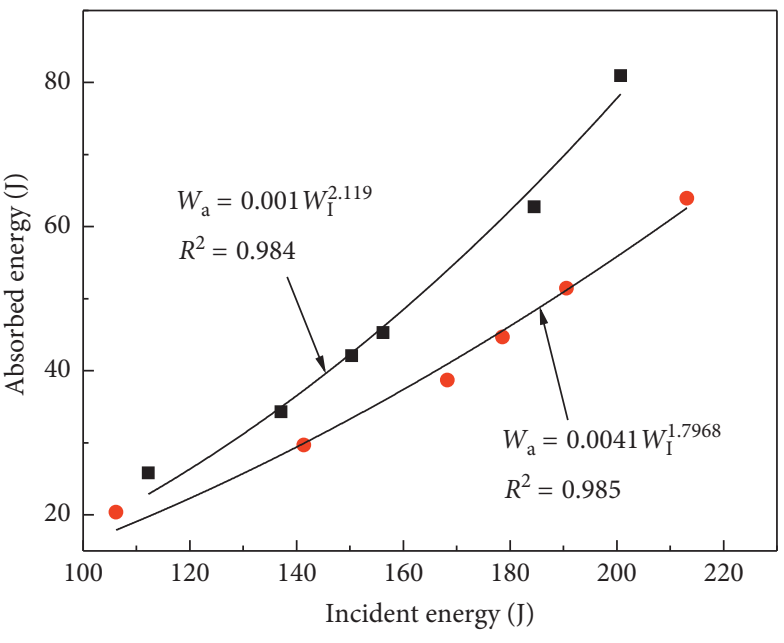

- US specimens

- RS specimens

_ Fitting line

(a)

(b)

FIGURE 10: Relation between energy and incident energy. (a) The reflected and transmitted energy of specimens. (b) The absorbed energy of specimens. 


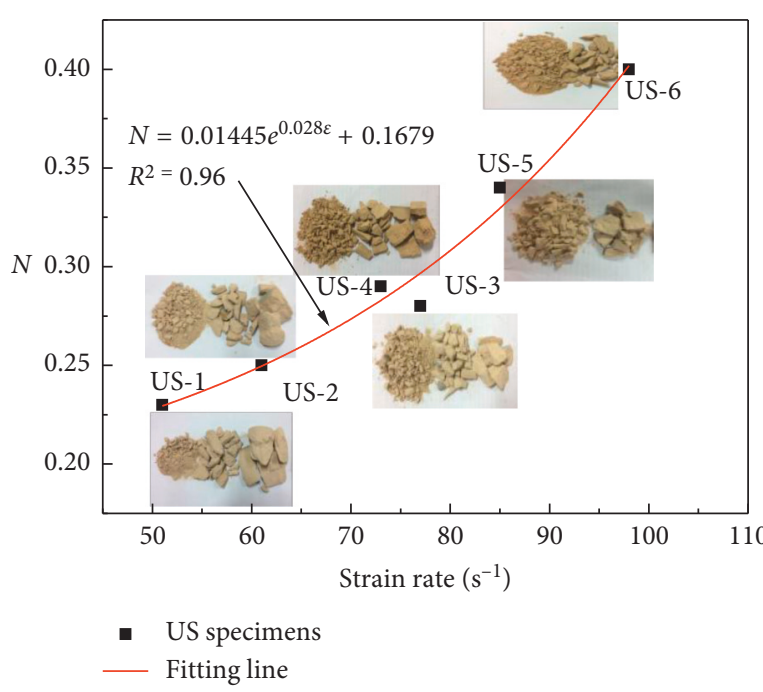

(a)

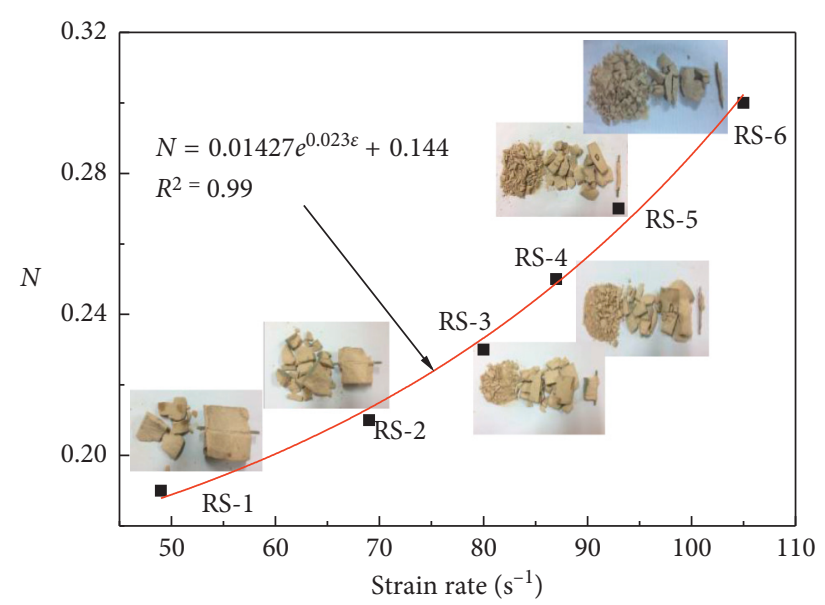

- RS specimens Fitting line

FIGURE 11: Relation between energy dissipation ratio and strain rate. (a) US samples. (b) RS samples.

increase of strain rate, reflecting the obvious correlation of strain rate. Comparing the energy characteristics of US and RS samples, it is known that the absorbed energy and transmitted energy of the unreinforced specimen are higher than that of the reinforced specimen, while the reflected energy of the unreinforced specimen is lower than that of the reinforced specimen (Figure 10). As shown in Figure 11, the energy dissipation rate increases with the increase of strain rate, and the increased rate of the unreinforced specimen is slightly higher than that of the reinforced specimen. Under the same strain rate, compared with the unreinforced specimen, the less the energy dissipation of the reinforced specimen, the more difficult the crack propagation, and the smaller the destruction degree, the greater the fragment (Figure 11).

\section{Discussion}

With increasing coal mining depth and growing coal output, the geological and mining conditions have changed complicated considerably [35], and roadway instability has been a major concern for researchers. Floor heave, roof falling off, and splitting failure of roadway are often occurred. Roadway stability is analyzed from the viewpoint of energy. The energy is dissipated in the form of wave propagation in the rock. A graph of wave propagation in the interior of the reinforced specimen is shown in Figure 12. When the incident energy comes from the rock, three components of the energy are divided, namely, the absorbed energy, reflected energy, and transmitted energy. From the performance of reinforced specimen, as discussed in Sections. 3 and 4, it is indicated that the dynamic strength and deformation ability of rock were enhanced by applying rockbolt, and the absorbed energy of the reinforced specimen was reduced. This is because the lateral confining pressure $\sigma_{3}$ is equivalently applied by inserting the bolt in rock mass (Figure 12(b)); the material strength parameters of rock mass were improved [36], which improves the strength of the rock mass and restricts the crack propagation. Therefore, at the same incident energy, the more difficult the crack propagation of reinforced sample, the less the absorbed energy [37]. When the roadway reinforced by the rockbolt is subjected to dynamic loading, the rockbolt can share load, increasing the strength of roadway surrounding rock, so the deformation of roadway surrounding rock will be restricted. Furthermore, most of energy is transmitted in the form of reflected energy, and little absorbed energy is used to break the reinforced surrounding rock, so the roadway will retain stability.

\section{Conclusions}

The experimental investigation of steel bar-reinforced sandstones under impact loading is presented in this paper. The strengths, energy characteristics, and failure patterns of unreinforced and reinforced samples were studied. The following conclusions can be drawn based on this study:

(1) The bolt can share the compressive stress of rock. The compressive strength of reinforced samples is greater than that of unreinforced samples under dynamic loading. And, the dynamic strength increases with the increase of strain rate, reflecting a strong correlation with the strain rate.

(2) The reflected energy and absorbed energy increase with the increase of incident energy, while the transmitted energy increases slightly. The higher the strain rate, the larger the energy dissipation rate and the higher the degree of fragmentation. It shows that the energy dissipation characteristic reflects the internal damage process to some extent. 


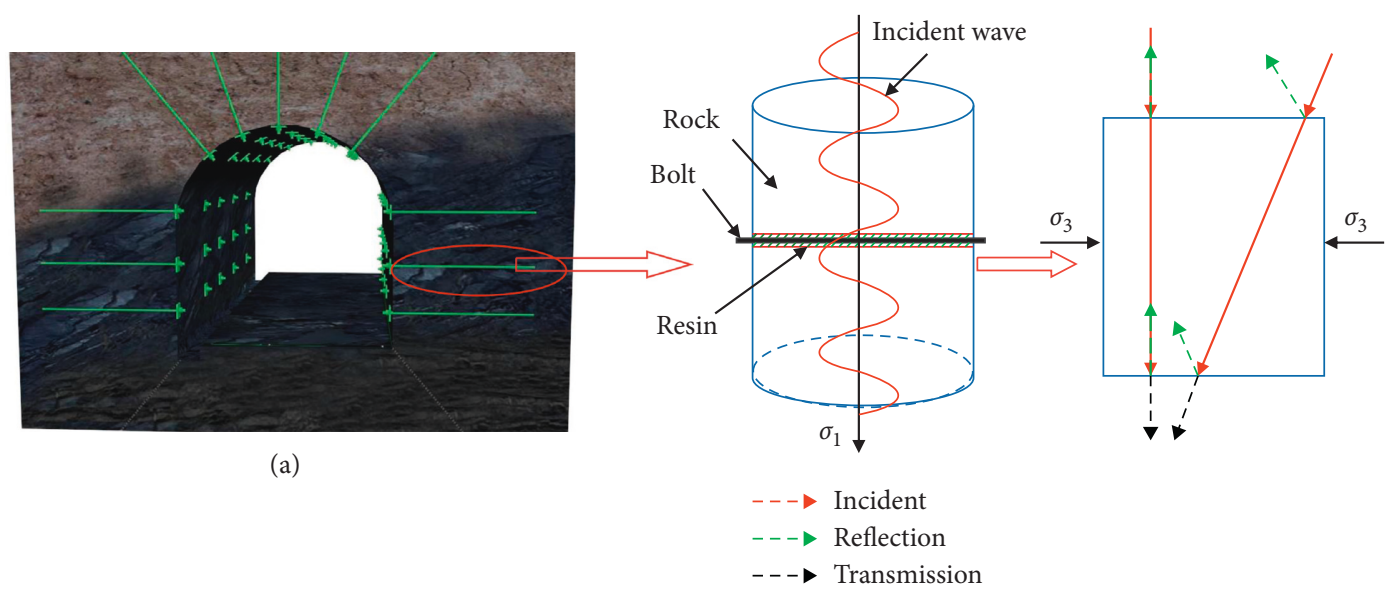

(b)

FIGURE 12: Graph of wave propagates in reinforced roadway. (a) Rockbolt reinforced roadway. (b) Waves propagate in interior of reinforced rock.

(3) The bolt has an important influence on the absorbed energy and failure characteristics of rock. Compared with unreinforced rock, the lesser the absorbed energy of reinforced rock, the smaller the damage degree. Consequently, the bolt can minimize failure of surrounding rock.

\section{Data Availability}

The data used to support the findings of this study are included within the article.

\section{Conflicts of Interest}

The authors declare that they have no conflicts of interest regarding the publication of this paper.

\section{Acknowledgments}

This work was supported by the Postgraduate Research and Innovation Project of Hunan Province (CX20190657) and the National Natural Science Foundation of China (51674041 and 51474103).

\section{References}

[1] M. Amini, A. Majdi, and Ö. Aydan, "Stability analysis and the stabilisation of flexural toppling failure," Rock Mechanics and Rock Engineering, vol. 42, no. 5, pp. 751-782, 2009.

[2] C. C. Li, "Field observations of rock bolts in high stress rock masses," Rock Mechanics and Rock Engineering, vol. 43, no. 4, pp. 491-496, 2010.

[3] H. Kang, Y. Wu, F. Gao, J. Lin, and P. Jiang, "Fracture characteristics in rock bolts in underground coal mine roadways," International Journal of Rock Mechanics and Mining Sciences, vol. 62, no. 6, pp. 105-112, 2013.

[4] M. C. He, J. Wang, X. M. Sun et al., "Mechanics characteristics and applications of prevention and control rock bursts of the negative Poisson's ratio effect anchor," Journal of China Coal Society, vol. 39, no. 2, pp. 214-221, 2014.
[5] M. S. Gao and N. Zhang, "Study of roadway support parameters subjected to rock burst based on energy balance theory," Journal of China University of Mining \& Technology, vol. 36, no. 4, pp. 426-430, 2007.

[6] K. Skrzypkowski, W. Korzeniowski, K. Zagórski, and P. Dudek, "Application of long expansion rock bolt support in the underground mines of Legnica-Głogów copper district," Studia Geotechnica et Mechanica, vol. 39, no. 3, pp. 47-57, 2017.

[7] K. Skrzypkowski, "Evaluation of rock bolt support for Polish Hard rock mines," E3S Web of Conferences, vol. 35, p. 8, 2018.

[8] C. Carranza-Torres, "Analytical and numerical study of the mechanics of rockbolt reinforcement around tunnels in rock masses," Rock Mechanics and Rock Engineering, vol. 42, no. 2, pp. 175-228, 2009.

[9] Y. Zhao and M. Yang, "Pull-out behavior of an imperfectly bonded anchor system," International Journal of Rock Mechanics and Mining Sciences, vol. 48, no. 3, pp. 469-475, 2011.

[10] B. Zhang, S. Li, K. Xia et al., "Reinforcement of rock mass with cross-flaws using rock bolt," Tunnelling and Underground Space Technology, vol. 51, pp. 346-353, 2016.

[11] Y. Cai, Y. Jiang, I. Djamaluddin, T. Iura, and T. Esaki, "An analytical model considering interaction behavior of grouted rock bolts for convergence-confinement method in tunneling design," International Journal of Rock Mechanics and Mining Sciences, vol. 76, pp. 112-126, 2015.

[12] M. Moosavi and R. Grayeli, "A model for cable bolt-rock mass interaction: integration with discontinuous deformation analysis (DDA) algorithm," International Journal of Rock Mechanics and Mining Sciences, vol. 43, no. 4, pp. 661-670, 2006.

[13] T. J. Freeman, "The behavior of fully-bonded rock bolts in the Kielder experimental tunnel," Tunnels Tunneling, vol. 10, no. 5, pp. 37-40, 1978.

[14] Q. B. Zhang and J. Zhao, "A review of dynamic experimental techniques and mechanical behaviour of rock materials," Rock Mechanics and Rock Engineering, vol. 47, no. 4, pp. 1411-1478, 2014.

[15] L. Weng, L. Huang, A. Taheri, and X. Li, "Rockburst characteristics and numerical simulation based on a strain energy density index: a case study of a roadway in Linglong gold mine, China," Tunnelling and Underground Space Technology, vol. 69, pp. 223-232, 2017. 
[16] X. Li, T. Zhou, and D. Li, "Dynamic strength and fracturing behavior of single-flawed prismatic marble specimens under impact loading with a Split-Hopkinson pressure bar," Rock Mechanics and Rock Engineering, vol. 50, no. 1, pp. 29-44, 2017.

[17] M. Tao, A. Ma, W. Cao, X. Li, and F. Gong, "Dynamic response of pre-stressed rock with a circular cavity subject to transient loading," International Journal of Rock Mechanics and Mining Sciences, vol. 99, pp. 1-8, 2017.

[18] X. Zhang, X. Ou, F. Gong, and J. Yang, "Effects of bedding on the dynamic compressive properties of low anisotropy slate," Rock Mechanics and Rock Engineering, vol. 52, no. 4, pp. 981-990, 2019.

[19] X. J. Hao, W. S. Du, Y. D. Jiang, D. Tannant, Y. Zhao, and Y. Guo, "Influence of bedding and cleats on the mechanical properties of a hard coal," Arabian Journal of Geosciences, vol. 11, no. 9, p. 200, 2018.

[20] Q. H. Wu, L. Chen, B. T. Shen, B. Dlamini, S. Li, and Y. Zhu, "Experimental investigation on rockbolt performance under the tension load," Rock Mechanics and Rock Engineering, 2019.

[21] M. He, C. Li, W. Gong, L. R. Sousa, and S. Li, "Dynamic tests for a constant-resistance-large-deformation bolt using a modified SHTB system," Tunnelling and Underground Space Technology, vol. 64, pp. 103-116, 2017.

[22] Y. Z. Wu, J. Y. Chen, J. K. Jiao et al., "Damage and failure mechanism of anchored surrounding rock with impact loading," Journal of China Coal Society, vol. 43, no. 9, pp. 2389-2397, 2018.

[23] Q. H. Wu, X. B. Li, L. Weng, Q. Li, Y. Zhu, and R. Luo, "Experimental investigation of the dynamic response of prestressed rockbolt by using an SHPB-based rockbolt test system," Tunnelling and Underground Space Technology, vol. 93, 2019.

[24] GB/T 50266-2013, Standard for Tests Methods of Engineering Rock Mass, Ministry of Housing and Urban-rural Development of the People's Republic of China, Beijing, China, 2013.

[25] X. B. Li, T. S. Lok, and J. Zhao, "Dynamic characteristics of granite subjected to intermediate loading rate," Rock Mechanics and Rock Engineering, vol. 38, no. 1, pp. 21-39, 2005.

[26] Z. Zhou, X. Li, A. Liu, and Y. Zou, "Stress uniformity of split Hopkinson pressure bar under half-sine wave loads," International Journal of Rock Mechanics and Mining Sciences, vol. 48, no. 4, pp. 697-701, 2011.

[27] K. Skrzypkowski, "Laboratory testing of a long expansion rock bolt support for energy-absorbing applications," E3S Web of Conferences, vol. 29, Article ID 00004, 9 pages, 2018.

[28] B. Lunberg, "A split Hopkinson bar study of energy absorption in dynamic rock fragmentation," International Journal of Rock Mechanics and Mining Science \& Geomechanics Abstracts, vol. 13, no. 6, pp. 187-197, 1976.

[29] Z. X. Zhang, S. Q. Kou, L. G. Jiang, and P.-A. Lindqvist, "Effects of loading rate on rock fracture: fracture characteristics and energy partitioning," International Journal of Rock Mechanics and Mining Sciences, vol. 37, no. 5, pp. 745-762, 2000.

[30] H. P. Xie, R. D. Peng, Y. Ju et al., “On energy analysis of rock failure," Chinese Journal Of Rock Mechanics And Engineering, vol. 24, no. 15, pp. 2603-2608, 2005.

[31] X. S. Liu, J. G. Ning, Y. L. Tan, and Q. H. Gu, "Damage constitutive model based on energy dissipation for intact rock subjected to cyclic loading," International Journal of Rock Mechanics and Mining Sciences, vol. 85, pp. 27-32, 2016.

[32] Z. Z. Xie, N. Zhang, Y. X. Yuan, G. Xu, and Q. Wei, "Study on safety control of composite roof in deep roadway based on energy balance theory," Sustanability, vol. 11, no. 13, p. 3688, 2019.

[33] L. Y. Li, H. P. Xie, Y. Ju, X. Ma, and L. Wang, "Experimental investigations of releasable energy and dissipation energy within rock," Engineering Mechanics, vol. 28, no. 3, pp. 35-40, 2011.

[34] X. Li, Y. Zou, and Z. Zhou, "Numerical simulation of the rock SHPB test with a special shape striker based on the discrete element method," Rock Mechanics and Rock Engineering, vol. 47, no. 5, pp. 1693-1709, 2014.

[35] H. P. Kang and J. H. Wang, Rock Bolting Theory and Complete Technology for Coal Roadways, China Coal Industry Publishing House, Beijing, China, 2007.

[36] X. G. Zhu, Q. Yang, and M. T. Luan, "Study of reinforcement effect of anchored rock masses and analytic constitutive equation for rock bolt," Rock and Soil Mechanics, vol. 38, no. 3, pp. 527-533, 2007.

[37] Y. C. You, E. B. Li, Y. H. Tan et al., "Analysis on dynamic properties and failure characteristics of salt rock based on energy dissipation principle," Chinese Journal of Rock Mechanics and Engineering, vol. 36, no. 4, pp. 843-851, 2017. 


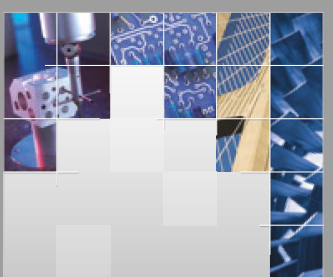

\section{Enfincering}
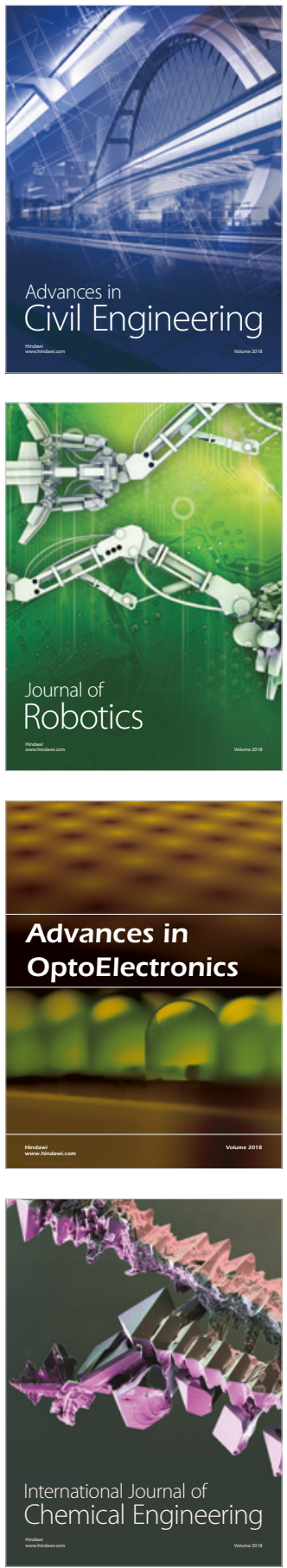

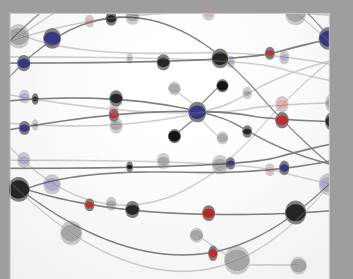

\section{Rotating \\ Machinery}

The Scientific World Journal

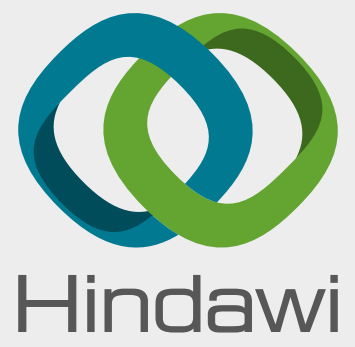

Submit your manuscripts at

www.hindawi.com
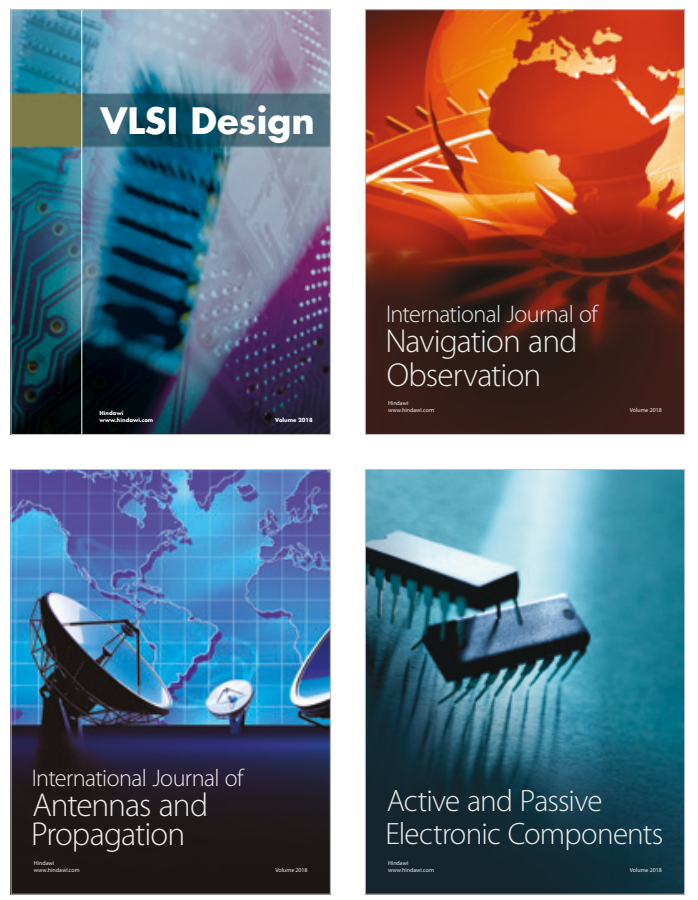
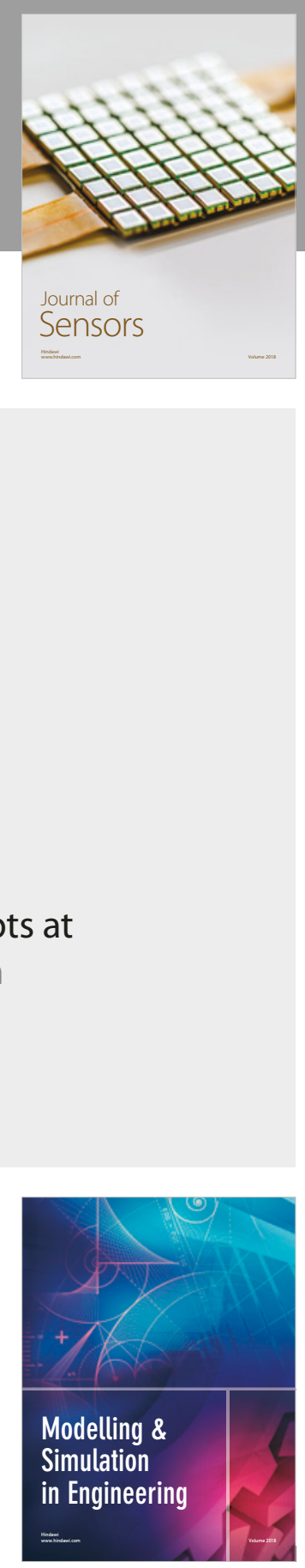

\section{Advances \\ Multimedia}
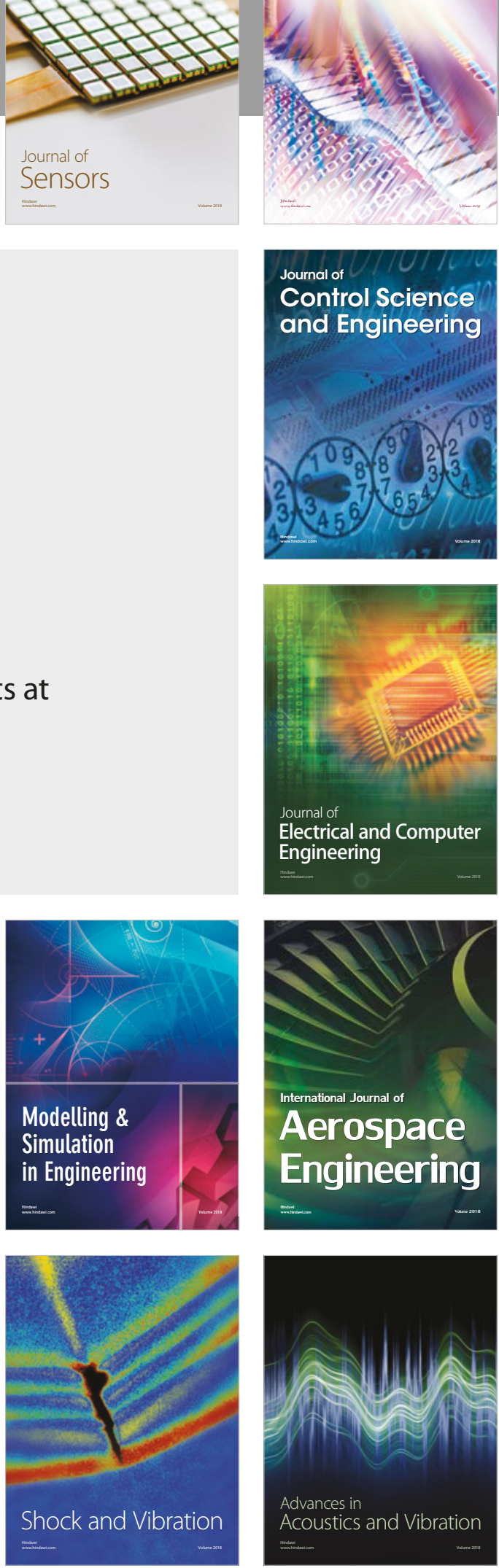